\title{
Trypanosoma Cruzi and Domestic Animals
}

Massimo Giangaspero*

Faculty of Veterinary Medicine, University of Teramo, Italy

*Corresponding author: Giangaspero M, Faculty of Veterinary Medicine, University of Teramo, Strada Provinciale 18, 64020 Piano d'Accio, Teramo, Italy, E-mail: giangasp@gmail.com

Received date: June 05, 2017; Accepted date: June 07, 2017; Published date: June 09, 2017

Copyright: $\odot 2017$ Giangaspero M. This is an open-access article distributed under the terms of the Creative Commons Attribution License, which permits unrestricted use, distribution, and reproduction in any medium, provided the original author and source are credited.

\begin{abstract}
Chagas disease is one of the most important zoonosis affecting the Latin America. Despite important progress achieved in last decades through strategies at regional level against vectoral transmission and improvement of screening among blood donors, the disease continues to represent a public health priority. Knowledge on epidemiology of the etiological agent Tripanosoma cruzi is of outmost importance to counter this serious disease, with the potential to cause significant morbidity and mortality in humans. Many animal species are sensible to the infection, but their epidemiological role in sylvatic and peri domestic cycles have not been always elucidated. Therefore, attention should be paid by veterinarians especially on domestic animals in order to clarify their potential role as reservoir close to human communities.
\end{abstract}

Keywords: Domestic animals; Epidemiology; Trypanosoma cruzi

\section{Editorial}

The Trypanosoma cruzi assumes a particular interest due to its geographic specificity and impact on human health. The American human trypanosomiasis, also known as Chagas disease, caused by Trypanosoma cruzi and transmitted by bugs (triatomes of the Reduvidae family), is probably the most important zoonosis typically south-American, with 6 to 7 million of cases reported to the World Health Organization (WHO), but with estimations reaching up to 13 million, with 3-3.3 million of symptomatic cases and an annual incidence of 200,000 cases [1,2], primarily in endemic zones of countries in Latin America where more than 100 million of people are exposed, and it is responsible of more than 10,000 deaths per year [1]. A disease that continues to represent a public health priority, despite important progress achieved in last decades through strategies applied at regional level against vectoral transmission and improvement of transfusion safety by screening among blood donors.

Despite the clear importance of the disease, its epidemiology is not always sufficiently known or updated even in the human population. For example, the French Guyana, located in the middle of this serious epidemiological situation, for long time seemed spared and considered as a low risk zone for the emergence of the Chagas disease. In 1940, a first case has been described, followed by very rare other reports [3-5]. But this believe was simply based on the absence of diagnosis, mainly due to the lack of cardiologists for long time. The starting of regular cardiological consultations at Cayenne changed rapidly this notion revealing a rising number of cases of clinical suspicion compatible with an infection due to T. cruzi as well as confirmed cases [6]. The 36 confirmed cases in 2005 [6] in absence of a surveillance system, suggest that the infection is probably under-diagnosed in the country. In addition, 70 to 80 patients hospitalized every year show signs of cardiac involvement compatible with the chronic form of Chagas disease. According to a quantitative estimation of the disease in French Guyana, and in the neighboring countries of Guyana and Suriname, the serological prevalence corresponded to about $1.2 \%$ of the human population [7].

All mammals are susceptible to the infection. Therefore, the disease is a zoonosis with an important domestic and wild animal reservoir. Domestic species as dogs, cats, large and small ruminants, rabbits and horses, and more than 150 wild animal species, including armadillo, racoon and vampire bat Desmodus rotundus, are potential reservoirs [8]. Exception made for dogs and apes that can develop severe clinical forms, T. cruzi is able to infect domestic and wild animals in Latin America with no or almost negligible clinic and economic impact. A possible interference with diagnostic for another animal trypanosomiases as T. vivax may occur. At contrary, this is important for the diffusion of the disease to man. An important number of animal species take part to the maintain of the infection being potentially infected and making the epidemiology of this disease particularly complex. The wild fauna plays a relevant role. For example, marsupials like the opossum (Didelphis marsupialis), locally named as "Pian" or " Manicou ", are frequently infected and represent a real reservoir and biological vector by the typical stercorarian cyclical transmission of T. cruzi, diffusing the parasite through their excreta, corresponding to the process occurring in the Triatominae insects. Another example is given by the high frequency of infection observed in certain wild species, and the ways of maintenance of such infections within the species. The majority of Molossus molossus, south American species of insectivorous bats, result infected (up to 80\%) as well as the almost totality of their fetuses, indicating a very high susceptibility and regular vertical transmission [9]. Even poultry, which are not sensible to the infection, play a supporting role for the maintain of the risk by nourishing the triatomines population peri domiciliary. Nevertheless, in veterinary medicine only some cases have been detected in dogs in the territory of the French Guyana. The recent emergence of canine trypanosomiasis at Cayenne was revealed through the detection of 20 cases characterized by high mortality (75\%) between 2003 and 2005 [6]. Among species of the wild fauna, the first described natural hosts of T. cruzi in French Guyana were the armadillo and the opossum (D. marsupialis) $[10,11]$. Out of the four species of armadillo present in Guyana (Cabassous unicinctus, Kappler 
Page 2 of 3

- Dasypus kappleri, giant - Priodontes maximus, and nine bands armadillos), two reservoir species have been identified: the ninebanded armadillo (Dasypus novemcinctus) and the southern nakedtailed armadillo (Cabassous unicinctus). To this list other three species of marsupials have been added further: Philander opossum, Caluromys philander and Micaureus demerarae. A study conducted by Dedet et al. [12] on marsupial species demonstrated a T. cruzi infection rate of $31 \%$ in $D$. marsupialis and $6 \%$ in $P$. opossum. Recently, a positivity by PCR of $45 \%$ for $T$. cruzi have been described in various wild mammals in French Guyana [13].

Very few studies have been conducted on this topic in domestic ruminants: in Chile, $30 \%$ to $38 \%$ of goats were seropositive [14], in Paraguay, $8 \%$ of bovines and $10 \%$ of pigs resulted infected [15]. As in many other south American countries were no researches have been carried out, T. cruzi was never reported in domestic animals in French Guyana. Nevertheless, the problem of exposure to the infections by $T$. cruzi concerns the majority of cattle in Latin America, approximately a quarter of the world bovine population, 280 million heads.

The parasite can be vehiculated to humans from these mammal reservoirs through the hematophagous vectors, and the zoonotic potential is high in south America, where triatomes maintain the peri domestic cycle and colonize houses [2]. Despite originally Chagas disease was basically sylvatic, the domestic cycle of transmission become independent and much more important [16].

Humans and animals can be infected by conventional direct transmission via the triatomes Reduvidae or by ingestion of infectious forms of T. cruzi present in these insects or in their excreta [8], or in absence of insect vectors, through the consumption of food and feed contaminated by opossum feces. The outbreaks of acute Chagas disease due to parasite oral-digestive transmission are a well-known phenomenon. This explain the number of family infections due to food contaminated by bug feces [17] or from opossum. Recently, a first outbreak of Chagas disease in French Guyana, with highly probable oral infection mode, have been reported on eight patients from a single family, subsequent to the ingestion of Oenocarpus bacaba palm juice [18]. Taking into account that the blood circulating forms of T. cruzi are transmissible [19], the ingestion of raw meat from infected animals can cause infections in men and animals. For instance, as for T. gondii, the exposition linked to meat consumption (bovine, ovine, caprine, but also pork or game) highlight the potential risk related to the difference of cooking temperature and time, appropriate cooking of meat will limit risk. Similarly, hygiene in manipulating raw meat will prevent possible contamination.

The role of domestic ruminants in the epidemiology of Chagas disease remains unknown, but their important number, the species of triatomes that can feed on cattle, as well as the direct and indirect contact with the human population indicate the potential of zootechnic sector as basin for the maintain of the infection which merit to be investigated. Furthermore, recent reports indicate the potential evolution of the pathogenic agent with appearance of parasite populations naturally resistant to nifurtimox and benznidazole, the two first choice active molecules for the treatment of the disease in man $[20,21]$. This might be in relation with the selective pression on parasites through the use of imidazole derivates in veterinary medicine.

\section{References}

1. World Health Organisation (WHO) (2017) Chagas disease (American trypanosomiasis) Fact sheet Updated March.

2. Tropical Diseases, Special Programme for Research and Training (TDR) (2017) Disease Watch Focus: Chagas disease TDR Nature Reviews Microbiology.

3. Floch H, Tasque P (1940) Un cas de maladie de Chagas en Guvane française. Institut Pasteur Guyane et Territoire de l'Inini 2: 4.

4. Chippaux JP, Dedet JP, Geoffroy B, Tavakilian G, Pajot FX (1983) La maladie de Chagas en Guyane française, in La Nature et 1'Homme en Guyane. ORSTOM et Institut Pasteur de la Guyane française, Cayenne 32.

5. Beaudet B, Esterre P, Jacquet-Viallet P, Ganty J, Dedet JP (1985) Un cas de cardiopathie chagasique chronique autochtone en Guyane française. Bull Soc Path exot 78: 56-63.

6. Jeannel D, Noireau F, Chaud P (2005) Emergence de la maladie de Chagas en Guyane française. Rapport dévaluation. Département international et tropical, Institut de veille sanitaire, Laboratoire hospitalo-universitaire de parasitologie-mycologie - Centre hospitalier Andrée Rosemon de Cayenne (LHUPM-CHAR).

7. Health Pan-American Organization HPO/WHO/NTD/ID (2006) Estimación cuantitativa de la enfermedad de Chagas en las Américas. Organización Panamericana de la Salud, Washington DC, USA, OP5/HDM/CD/425-0G.

8. Anonyme (1991) Lutte contre la maladie de Chagas. OMS Serie Rapports Techniques, Genève.

9. Añez N, Crisante G, Soriano PJ (2009) Trypanosoma cruzi congenital transmission in wild bats. Acta Tropica 109: 78-80.

10. Floch H, Lajudie P (1941) Recherches sur la trypanosomiase humaine américaine en Guyane française. Institut Pasteur Guyane et Territoire de l'Inini 21: 6.

11. Floch H, Lajudie P (1942) Cabassus lugubris et Didelphis cancrivora naturellement infectés par S. cruzi en Guvane française. Trimtona rubrofasciata vecteur naturel. Inst Pasteur Guyane et de l'Territoire Inini 45: 5.

12. Dedet JP, Chippaux JP, Goyot P, Pajot FX, Tibayrenc M, et al. (1985) Les hôtes naturels de Trypanosoma cruzi en Guyane française. Endémicité élevée du zymodème $1 \mathrm{chez}$ les marsupiaux sauvages. Annales de parasitologie humaine et comparée 60: 111-117.

13. Péneau J, Blanchet D, de Thoisy B, Aznar C (2014) Genetic diversity of Trypanosoma cruzi circulating in mammals and triatomines collected in urban areas, in French Guiana. Academic J Suriname 5: 456-460.

14. Alcaino TV, Lorca M, Nunez F, Issota A, Gorman T (1995) Chagas' disease in goats from the Metropolitan region (Chile). seroepidemiological survey and experimental infection. Parasitol. al Día 19: 30-36.

15. Fujita O, Sanabria L, Inschaustti A, De Arias A, Tomizawa Y, et al. (1994) Animal reservoirs for Trypanosoma cruzi infection in an endemic area in Paraguay. J Med Sci 56: 305-308.

16. Deane LM (1964) Animal reservoirs of Trypanosoma cruzi in Brazil. Revista Brasileira de Malariologia e Doencas Tropicais 16: 27-48.

17. Lainson R, Shaw JJ, Naiff RD (1980) Chagas' disease in the Amazon Basin: speculations on transmission per os. Rev Inst Med trop S Paulo 22: 294-297.

18. Blanchet D, Brenière SF, Schijman AG, Bisio M, Simon S, et al. (2014) First report of a family outbreak of Chagas disease in French Guiana and post treatment follow-up. Infect Genet Evol 28: 245-250.

19. Dias E (1940) Transmissao do Schizotrypanum cruzi entre vertebrados por via digestiva. Brasil Medico 54: 775.

20. Filardi LS, Brener Z (1987) Susceptibility and natural resistance of Trypanosoma cruzi strains to drugs used clinically in Chagas disease. Trans R Soc Trop Med Hyg 81: 755-759.

21. dos Santos PF, Ruiz JC, Soares RPP, Moreira DS, Rezende AM, et al. (2012) Molecular characterization of the hexose transporter gene in 
Citation: Giangaspero M (2017) Trypanosoma Cruzi and Domestic Animals. Clin Microbiol 6: e142. doi:10.4172/2327-5073.1000e142

Page 3 of 3

benznidazole resistant and susceptible populations of Trypanosoma cruzi.

Parasit Vectors 5: 161. 